\title{
ASPECTOS GEOLÓGICOS DE ALGUMAS INTRUSÕES KIMBERLÍTICAS DA REGIÃO DE PARANATINGA, MATO GROSSO
}

\author{
RICARDO K. WESKA ${ }^{1} \&$ DARCY P. SVISERO ${ }^{2}$
}

\begin{abstract}
RESUMO Diversas intrusões de natureza kimberlítica ocorrem na região de Paranatinga, localizada na porção centro-nordeste do Estado de Mato Grosso, espalhadas por uma área de 40x 100km, aproximadamente, constituindo o Campo Kimberlítico de Paranatinga. Este trabalho apresenta uma síntese das informações geológicas disponíveis no momento a respeito de algumas intrusões representativas deste campo kimberlítico A intrusão Piranha I, possui forma elipsoídica, dimensōes principais $470 \times 260 \mathrm{~m}$ e área de 9,6 ha. Trata-se de um kimberlito rico em flogopita, contendo ainda granada, ilmenita, zircão, megacristais de diopsídio gemológico, além de uma grande quantidade de xenólitos crustais da Fm. Diamantino. A intrusão Alabama, possui também forma elipsoídica, dimensōes de $150 \times 90 \mathrm{~m}$ e área de 1,06ha. Destaca-se pela grande quantidade de ilmenita e por xenólitos de basaltos toleíticos. O corpo K3, cujo solo de alteração contém granada, ilmenita e diopsídio, por sua vez, possui forma de pêra, dimensões de 240 x 140m, caracterizando-se por preservar a parte superior da estrutura do diatrema. Quanto ao Batovi 6, trata-se de um corpo elipsoídico, de $280 \times 80 \mathrm{~m}$, área de 1,76 ha, cujo destaque é a presença de xenólitos de granada lherzolito.
\end{abstract}

Palavras-chave: Kimberlito, Campo kimberlítico, diamante. Mato Grosso, Brasil

\begin{abstract}
GEOLOGIC ASPECTS OF SOME KIMBERLITE INTRUSIONS IN THE PARANATINGA REGION. MATO GROSSO, BRAZIL In this paper we summarise the main geological features of some selected intrusions from the Paranatinga Kimberlite Field, located in center-northeas Mato Grosso State, Brazil. The field comprises an area of $40 \times 100 \mathrm{~km}$ and lies at the southern border of the Amazonian Craton. The Piranha I kimberlite covers an area of 9.60 ha and contains large amounts of phlogophite. In addition, it contains garnet, ilmenite, zircon, megacrysts of gemmological diopside and crustal xenoliths of the Diamantino Formation. The Alabama intrusion has an area of 1.06 ha being rich in ilmenite and crustal xenoliths of tholeitic basalt. The K3 is a pear-shaped intrusion whit a preserved crater facies whose weathered soil contains garnet, ilmenite and diopiside. As for the Batovi 6 kimberlite, it covers an area of 1,76ha and contains garnet lherzolite xenoliths.
\end{abstract}

Keywords: kimberlite, kimberlitic field, diamond, Mato Grasso, Brazil

INTRODUÇÃo Apesar do diamante ser conhecido no estado de Mato Grosso desde o final do século dezoito (Baxter 1980, Abreu 1973), a prospecção de fontes primárias só foi desenvolvida no início dos anos 70. Desde essa época, diversas empresas de mineração vêm atuando periodicamente no estado, fato que conduziu à descoberta de um grande número de intrusões com características de kimberlito. Muitas destas informações permanecem no âmbito de relatórios de cmpresas de mineração, de tal modo que o número de corpos, as dimensões e a forma e outras características de natureza econômica não são conhecidas, constituindo um quadro que pode ser aplicado a outras regiões diamantíferas do País.

As primeiras informações sobre kimberlitos na região de Paranatinga foram apresentadas por Fragomeni (1976), o qual propôs a existência de uma Província Kimberlítica na região constituída por aproximadamente quatro dezenas de intrusões. Davis (1977) datou o kimberlito Batovi 9 pelo método U/Pb em zircão, obtendo idade de $121 \mathrm{Ma}$. Svisero \& Meyer (1986) apresentaram dados de química mineral de granada e ilmenita da intrusão Batovi 6, situada nas cabeceiras do rio homônimo, identificando granada G9 e ilmenita magnesiana. Costa (1996), comparou dados químicos do kimberlito Batovi 6 com as intrusões Três Ranchos 4 e Limeira, situadas na região de Coromandel, Minas Gerais. Bizzi et al. (1998) comparou as características isotópicas de algumas intrusões de Paranatinga com intrusões das localidades de Jaibaras e Coromandel. Filemon et al. (1997) apresentaram uma descrição minera-lógica e petrográfica preliminar de dois furos de sondagens da intrusão Piranha 1 localizada na margem esquerda do rio homônimo. Pinho et al. (1994) definiram a forma e as dimensões das intrusões B6 (Córrego da Boa Esperança), B7 (Córrego Lageado), Gavião 1 e 2, combinando levantamentos magnetométricos e gravimétricos. Heaman et al. (1998), utilizando o método U/Pb em zircão obteve idades entre 122,6 a 126,3 Ma. para algumas intrusões de Paranatinga, concordando com a determinação anterior de Davis (1977). Greenwood et al. (1999), apresentaram uma caracterização geológica ampla (fácies, petrografia, química mineral e isotopia) do B6 (fácies diatrema) e outros corpos da região de Paranatinga (fácies cratera), os quais estão distribuídos em uma área de $4000 \mathrm{~km}^{2}$. Weska e Svisero (2001) sintetizaram informações geológicas a respeito das intrusões das regiões de Paranatinga, Juína e Poxoréu.

Neste trabalho são apresentadas novas informações de algumas intrusões de Paranatinga, compreendendo: localização precisa das intrusões, levantamento geológico dos corpos e das rochas encaixantes, xenólitos crustais, guias de prospecção, descrição macroscópica de alguns testemunhos de sondagem,

1 Departamento de Recursos Minerais, Instituto de Ciências Exatas e da Tena, Universidade Federal de Mato Grosso, Av. Fernando Corrêa s/n . Cidade Universitária, Bairro Coxipó, CEP 78.(06()-9()), Cuiabá, MT. e-mail: weska@terra.com.br

2 Departamento de Mineralogia e Geotectônica, Instituto de Geociências, Universidade de São Paulo, Rua do Lago .562, CEP ()5508-90(), São Paulo, SP. e-mail: svisero@usp.br 
assim como um novo contexto geológico adjacente às intrusões. Serão discutidas com alguns pormenores as intrusões $\mathrm{K} 3$, Alabama (KA), Batovi 6 (B6) e Piranha 1 (P1); além disso, serão apresentadas informações preliminares das intrusões Corgão 1 (CG1), Gavião 1 (G1) e 2 (G2), Batovi 7 (B7) e Piranha 2; além dos furos PAP 15 e 16 . Os testemunhos de sondagem da região de Paranatinga são de dois tipos: a) contínuos e b) em chips (fragmentos), e encontram-se depositados no Departamento de Recursos Minerais da Universidade Federal de Mato Grosso (UFMT), tendo sido doados a esta Instituição pela Rio Tinto Desenvolvimentos Minerais (RTDM). O testemunho de sondagem do kimberlito Alabama foi doado pela RTDM à Universidade Federal de Ouro Preto.

O CONTEXTO GEOLÓGICO Os kimberlitos da região de Paranatinga situam-se à $\mathrm{N}$ da Faixa de Dobramentos Paraguai, estão posicionados na borda do Cráton Amazônico (Fig. 1) e distribuídos em área de aproximadamente $4.000 \mathrm{~km}^{2}$ (Santos \& Loguercio 1984). As intrusões ocorrem junto às drenagens dos tributários do rio Xingu pela margem esquerda, destacando-se entre eles os rios Batovi, Jatobá e Curisevo, os quais emprestam nome para parte das intrusões conhecidas.

O contexto geotectônico da região de Paranatinga (Fig. 1) a partir do Ciclo Brasiliano é caracterizado pelo transporte tectônico das rochas do Grupo Alto Paraguai (Almeida 1964) sobre o SE do Cráton Amazônico, fato evidenciado por falhas de empurrão, bem como por dobras em chevron com vergência do plano axial e aumento da amplitude das dobras em direção à área cratônica localizada a N-NW. O dobramento em chevron está impresso em rochas da Formação Raizama, podendo ser observado nos afloramentos da Faixa Paraguai em cortes ao longo da estrada MT-130, situados a sul de Paranatinga, quando esta atravessa o conjunto de serras da Província Serrana

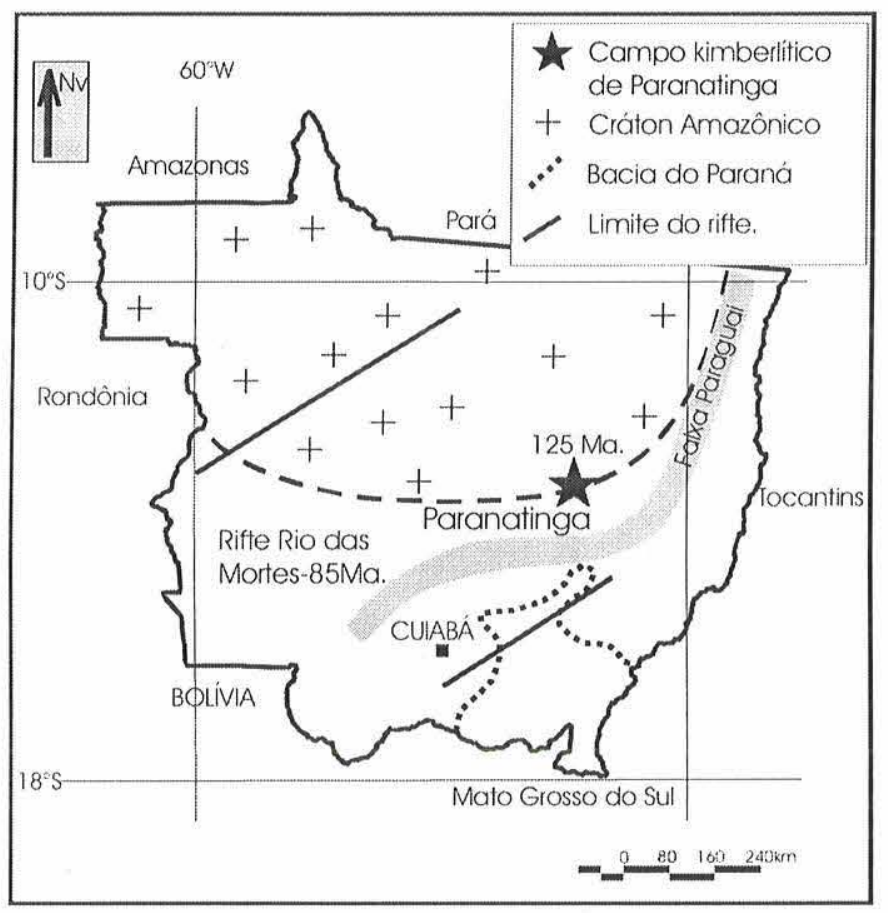

Figura 1 - Contexto geológico-tectônico do Campo Kimberlítico de Paranatinga.
(Almeida 1964). Horsts e grabens situados a norte (Bacia dos Parecis) e a sul (Bacia Bauru) da faixa de dobramentos (Fig. 1), registram os eventos relativos à evolução do Rifte Rio das Mortes, como resultado do impacto da Pluma de Trindade no centro-oeste brasileiro durante o Cretáceo (Weska 1996, Gibson et al. 1997).

Segundo Bardet (1973), as intrusões de Paranatinga estariam alinhadas ao longo do azimute $125^{\circ}$ constituindo uma mega sutura na crosta sul-americana com mais de $3000 \mathrm{~km}$ de extensão, passando pela borda norte da Bacia Intracratônica do Paraná, indo desde o estado do Rio de Janeiro até Rondônia, sendo conseqüência da separação continental entre a África e a América do Sul. Por outro lado, se de fato esta megaestrutura existisse, deveria haver em contrapartida brechas de falha/ milonitos em uma faixa de algumas centenas de $\mathrm{km}$, fato que não tem sido observado em trabalhos de campo ao longo deste hipotético lineamento. Um dado que aparentemente se contrapõe à existência deste megalineamento é o Rifte Rio das Mortes, localizado na borda NW da Bacia do Paraná e caracterizado por sua orientação marcante SW-NE (Weska 1996).

Com relação ao agrupamento hierárquico da ocorrência de rochas kimberlíticas na região de Paranatinga, as informações de campo conhecidas até o presente momento indicam que estes corpos se estendem em torno de uma área de aproximadamente $40 \times 100 \mathrm{~km}$. Estas dimensões são características de um campo kimberlitico, conforme definido por Mitchell (1986), o qual adotou como dimensão de referência um diâmetro de $50 \mathrm{~km}$. Ainda segundo Mitchell (1986), vários campos podem se reunir constituindo uma província kimberlítica que neste caso pode alcançar várias centenas de quilômetros. Mitchell (1986) cita como exemplo as províncias kimberlíticas da Sibéria e da África do Sul, constituídas por vários campos kimberlíticos, cujas dimensões ultrapassam 1000km. Nestas condições, acreditamos que o conjunto de kimberlitos existentes na região de Paranatinga constitua um campo kimberlítico e não uma província kimberlítica como referido anteriormente por diversos autores (Fragomeni 1976, Svisero e Cheregatti 1992, Weska 1993, Heaman et al. 1998).

O empilhamento estratigráfico das rochas adjacentes aos kimberlitos do Campo Kimberlítico de Paranatiga é constituído por arenitos arcoseanos, siltitos e argilitos da Formação Diamantino, topo do Grupo Alto Paraguai (Almeida 1964), de idade pré-cambriana superior, caracterizando o substrato geológico mais antigo. Pacotes pelíticos devonianos da Formação Ponta Grossa (Barros et al. 1980) afloram nas porções topograficamente inferiores do Rifte Rio das Mortes e são portadores de fósseis (brachiópodes?). Segundo as datações de Davis (1977) e Heaman et al. (1998), os corpos kimberlíticos de Paranatinga foram intrudidos durante o cretáceo inferior. Assim sendo, essas seriam as intrusões mais antigas conhecidas no estado de Mato Grosso, uma vez que as intrusões do Campo Kimberlítico de Juína, com idades de 92 a 95 Ma. são do Cretáceo (Heaman et al. 1998)

Em Paranatinga os pipes estão encaixados em rochas da Formação Diamantino, conforme evidenciado em contatos observados no campo e também pela presença de xenólitos abundantes de rochas desta unidade. O Alabama possui xenólitos crustais de composição basáltica. Basaltos em princípio não afloram na região, sendo mais antigos que as intrusões e similares aos basaltos Tapirapuã (MT) (Greenwood 2001).

Dos pipes conhecidos, o Batovi 6 é uma intrusão da fácies 
diatrema (Weska 1993, Costa 1996, Greenwood et al. 1999), enquanto que os demais preservam a fácies cratera (Greenwood et al. 1999). O corpo K3 tem as porções de caldeira preservada.

Um evento de basalto alcalino do Cretáceo Superior, sob as formas de derrame e dique, equivalentes à Formação Paredão Grande de idade de 83,9 $\pm 0,4 \mathrm{Ma}$. (Weska 1996), foi descrito nos furos PAP 20 e 23 (Fig. 2). Esses corpos ocorrem ainda nas margens do rio Batovi e próximo ao rio Ronuro, tendo sido descrito também no furo PAD 04 . O contato inferior do derrame (PAD 04) ocorre com o equivalente da Formação Cachoeira do Bom Jardim (Weska 1996), enquanto que o contato superior (PAP 20 e 23) ocorre com o equivalente da Formação Cambambe (Weska 1996). Tais corpos basálticos são similares aos descritos por Weska (1996) na porção SE do Rifte Rio das Mortes no município de Dom Aquino, pertencentes à Bacia Bauru. A Formação Cambambe, porção distal de leques aluviais do Grupo Bauru (Weska 1996), também ocorre na Bacia dos Parecis, recobrindo por discordancia erosiva parte dos corpos kimberlíticos, como por exemplo, o Alabama. Nos furos descritos por Greenwood et al. (1999), parte dos kimberlitos intercalam-se com a base das coberturas cretáceas. A Formação Cambambe em Paranatinga ocorre com interdigitações cíclicas de pacotes de clastos grossos (conglomerado e arenito conglomerático), arenito, siltito e argilito principalmente. Os pacotes estão muito silicificados e são hospedeiros de árvores petrificadas similares àquelas descritas por Barros et al. (1982), identificadas como pertencentes ao Cretáceo Superior: Considerando-se a idade de $85 \mathrm{Ma}$. dos derrames de basalto alcalino da Raizinha, os mais primitivos e antigos na evolução do Rifte Rio das Mortes, juntamente com a idade de $65 \mathrm{Ma}$. dos fósseis de árvores petrificadas (Campos e Castro 1978) e fósseis répteis (Roxo 1937), o embaciamento do rifte através das unidades clasto-químicas nas bacias Bauru e Parecis demandou $20 \mathrm{Ma}$.

Pacotes detrito-lateríticos de leques aluviais terciários e equivalentes à Formação Cachoeirinha (Gonçalves e Schneider 1968) recobrem as rochas mais antigas incluindo a Formação Diamantino, alguns pipes como o K3 e o Piranha 1, os derrames da Formação Paredão Grande, assim como a unidade Cambambe. A Formação Cachoeirinha guarda registros da peneplanização relativa à Superfície Sul-Americana (King 1956), que esculpiu o topo da superfície em planaltos como o dos Parecis.

Coberturas inconsolidadas de cascalho, areia e argila caracterizam os pacotes quaternários que concentram os principais depósitos diamantíferos aluvionares da região, como aqueles dos rios Batovi e Jatobá, entre outros.

\section{ASPECTOS GEOLÓGICOS DAS INTRUSÕES ESTU.}

DADAS Neste item serão sintetizadas as informações geológicas disponíveis para os kimberlitos K3, Piranha 1, Alabama e Batovi 6. Quanto à localização geográfica em relação a Paranatinga, o K3 situa-se a noroeste (Fig. 3A); o Alabama a norte (Fig. 3B); e o Batovi 6 e o Piranha I a nordeste (Figs. 3C e 3D). Outros corpos não aflorantes (CG1, PAP 15 e 16, B7, G1 e 2 e P2), foram localizados através de minerais indicadores presentes no solo sobre as intrusões ou a partir dos furos de sondagem (Fig. 3). A intrusão CGl possui importância histórica por ter sido o primeiro pipe descoberto no Campo Kimberlítico de Paranatinga. $\mathrm{O}$ acesso às intrusões K3, Alabama e Batovi 6 é feito através da estrada MT 130, no tre-
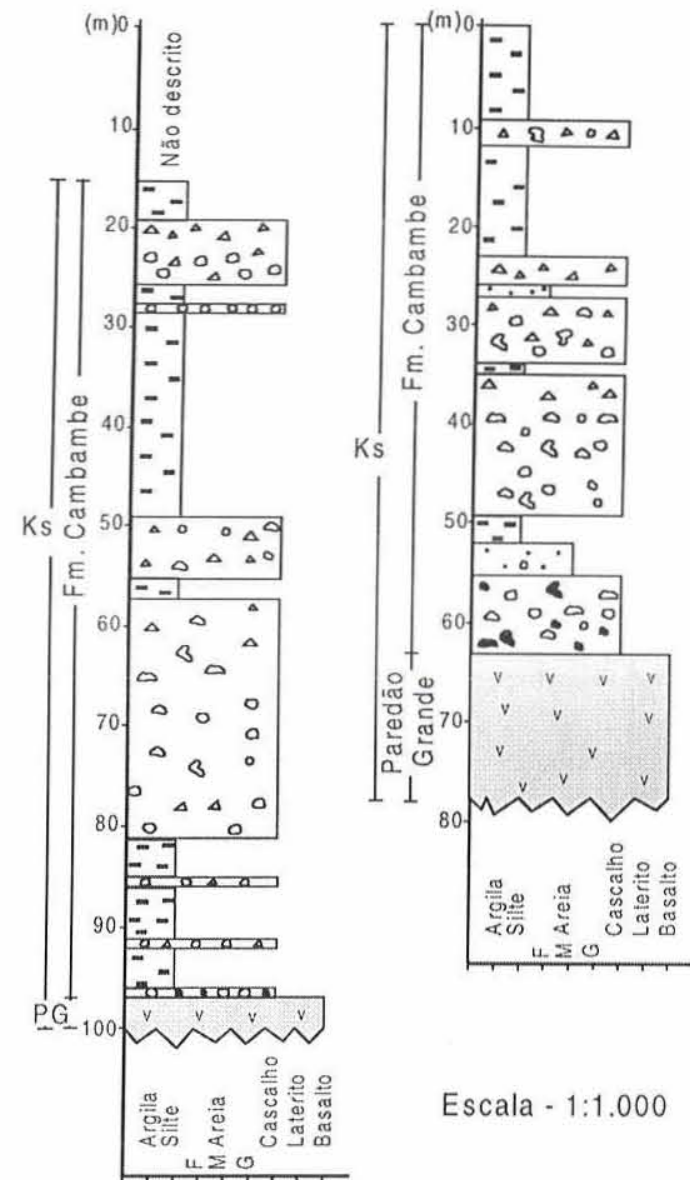

Escala - 1:1.000

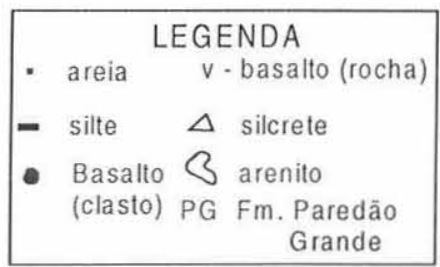

Figura 2. Furos de sondagem mostrando o contato entre as formações Paredão Grande e Cambambe

cho entre Paranatinga e Sorriso. O K3 situa-se na margem direita do rio Jatobá a $62 \mathrm{~km}$ da cidade de Paranatinga; o Alabama na grota do Ferro, afluente da margem esquerda do rio Batovi, a $87 \mathrm{~km}$ de Paranatinga, enquanto que o Batovi 6 localiza-se na margem direita do rio homônimo e a $32 \mathrm{~km}$ da referida cidade. $\mathrm{O}$ acesso aos corpos Piranha $\mathrm{I}$ e 2 é feito através da estrada que demanda de Paranatinga em direção à Gaúcha do Norte. Estes pipes situam-se na fazenda Mundo Acabado, sendo o Piranha 1 aflorante junto à margem do córrego Chicória, afluente da margem esquerda do rio Piranha.

Informações de localização por pares de coordenadas, dimensões, forma, área e xenólitos encontrados nas intrusões ora apresentadas estão expostas na Tabela 1. Dos corpos aqui apresentados o Piranha 1 é o de maior dimensão. Por outro lado, o Alabama difere dos demais por apresentar xenólitos de compo- 


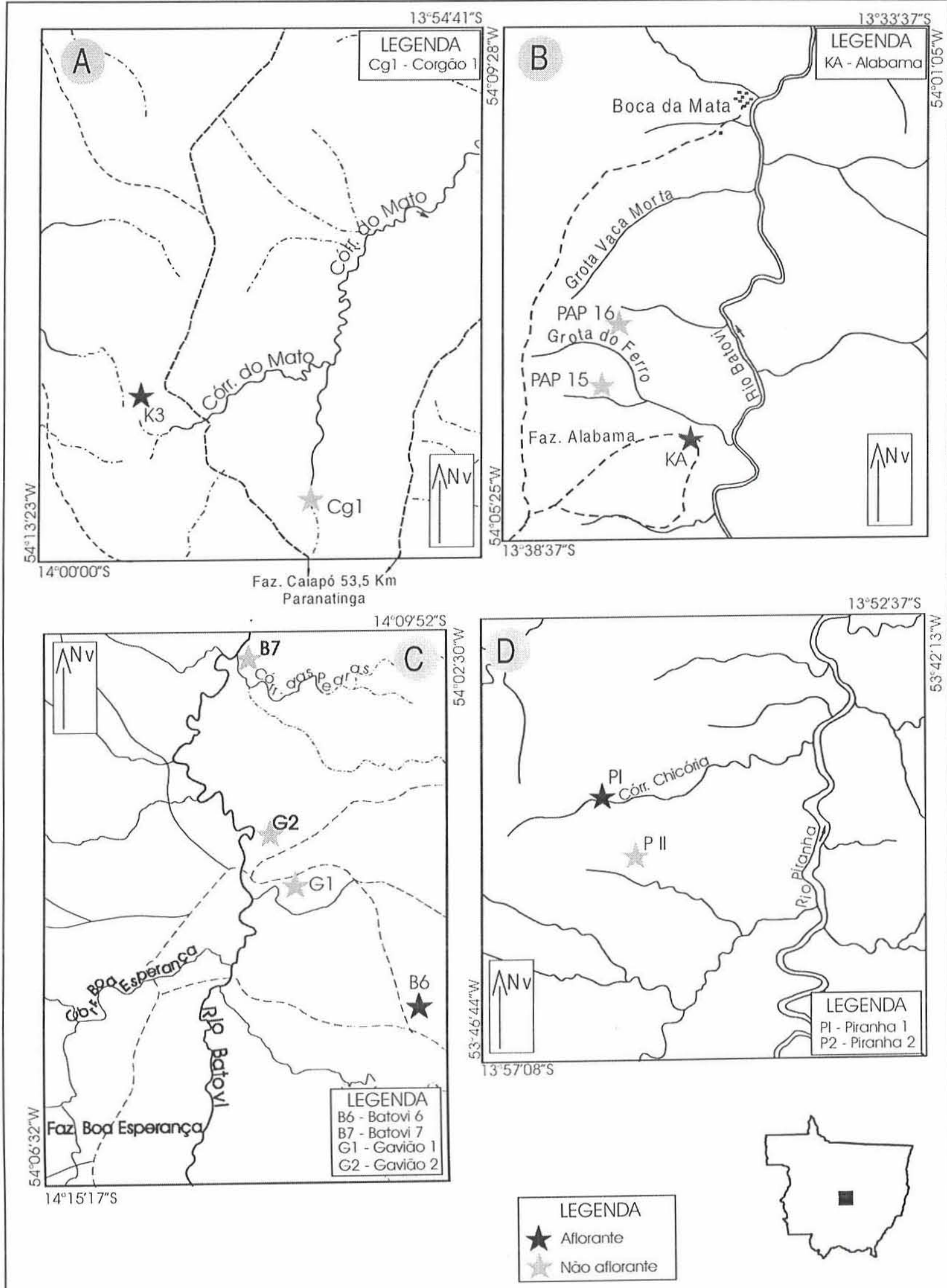

Fonte: mapas extraidos das folhas A e B: SD.21-X-D-VI (Boca da Mata); C: SD.21-Z-B-III (Paranatinga); e D: SD.22-Y-A-I (Ägua Emendada), respectivamente 1980, 1977 e 1977. Escala 1:100.000.

Figura 3 - Mapa de localização de algumas intrusões do Campo Kimberlítico de Paranatinga. 
Tabela I - Dados preliminares de algumas intrusões do Campo Kimberlítico de Paranatinga.

\begin{tabular}{|c|c|c|c|c|c|}
\hline CORPO & LOCALIZAÇÃO & DIMENSÕES (m) & FORMA & ÁREA(ha) & XENÓLITOS \\
\hline PIRANHA & $13^{\circ} 54^{\prime} 36^{\prime \prime} \mathrm{S}$ & \multirow[t]{2}{*}{$470 \times 260$} & \multirow[t]{2}{*}{ elipsoídica } & \multirow[t]{2}{*}{9,60} & \multirow[t]{2}{*}{ Fm. Diamantino } \\
\hline 1 & $53^{\circ} 45^{\prime} 28^{\prime \prime} \mathrm{W}$ & & & & \\
\hline PIRANHA & $13^{\circ} 56^{\prime} 32^{\prime \prime} \mathrm{S}$ & \multirow[t]{2}{*}{ - } & \multirow[t]{2}{*}{-} & \multirow[t]{2}{*}{ - } & \multirow[t]{2}{*}{ - } \\
\hline 2 & $53^{\circ} 45^{\prime} 40^{\prime \prime} \mathrm{W}$ & & & & \\
\hline ALABAMA & $13^{\circ} 37^{\prime} 55^{\prime \prime} \mathrm{S}$ & \multirow[t]{2}{*}{$150 \times 90$} & \multirow[t]{2}{*}{ elipsoídica } & \multirow[t]{2}{*}{1,06} & \multirow{2}{*}{$\begin{array}{c}\text { Fm. Diamantino e } \\
\text { de basalto }\end{array}$} \\
\hline & $54^{\circ} 03^{\prime} 15^{\prime \prime} \mathrm{W}$ & & & & \\
\hline \multirow[t]{2}{*}{ K3 } & $13^{\circ} 58^{\prime} 16^{\prime \prime} \mathrm{S}$ & \multirow[t]{2}{*}{$240 \times 140$} & \multirow[t]{2}{*}{ piriforme } & \multirow[t]{2}{*}{2,64} & \multirow[t]{2}{*}{ Fm. Diamantino } \\
\hline & $54^{\circ} 12^{\prime} 25^{\prime \prime} \mathrm{W}$ & & & & \\
\hline \multirow[t]{2}{*}{ BATOVI 6} & $14^{\circ} 13^{\prime} 40^{\prime \prime} \mathrm{S}$ & \multirow[t]{2}{*}{$280 \times 80$} & \multirow[t]{2}{*}{ elipsoídica } & \multirow[t]{2}{*}{1,76} & \multirow{2}{*}{$\begin{array}{l}\text { Fm. Diamantino, } \\
\text { granada Iherzolito }\end{array}$} \\
\hline & $54^{\circ} 02^{\prime} 43^{\prime \prime} \mathrm{W}$ & & & & \\
\hline
\end{tabular}

sição basáltica. Outros dados destas intrusões são apresentados a seguir.

Outro aspecto que merece destaque é a cor de alteração das rochas da regiã́o. O contraste entre a intrusão $\mathrm{e}$ a encaixante constitui, em alguns casos, um excelente guia de prospeç̧ão regional de kimberlito. Os corpos Piranha 1, Alabama e Batovi 6 destacam-se na paisagem pela cor marrom avermelhada dos solos de alteração que cobrem este corpos, contrastando com as cores branca e amarela dos solos derivados dos arenitos arcoseanos e rochas encaixantes da Fm. Diamantino. No caso do K3, o contraste não é tão nítido porque as rochas encaixantes da Fm. Diamantino são constituídas por siltitos c argilitos de cor vermelha tijolo, resultando em um solo semelhante ao do kimberlito. Alguns detalhes particulares de cada corpo serão apresentados em tópicos separados a seguir.

Piranha 1 Jesus \& Filemon (1997) mapearam e descreveram os testemunhos de sondagem PAP 08 e 09 (Fig. 4) referentes a esse corpo. Macroscopicamente, a intrusão Piranha I é verde escura quando pouco alterada, e verde clara quando muito alterada. É caracterizada pela abundância de fenocristais de gránada $(0,1$ a $0,5 \mathrm{~cm})$, flogopita $(0,1$ a $0,7 \mathrm{~cm})$, ilmenita $(0,1$ a 1 $\mathrm{cm})$ e zircão $(0,1 \mathrm{a} 1 \mathrm{~cm})$, diopsídio $(0,05 \mathrm{a} 3 \mathrm{~cm})$, assim como por xenólitos de argilito, siltito e arenito arcoseano a micáceo, principalmente de cor vermelha, pertencentes à Formação Diamantino. Os megacristais de diopsídio são aproveitados como material gemológico. Entre as intrusões estudadas, o Piranha 1 é a que possui a menor porcentagem de ilmenita. Os efeitos da segregação carbonática são observados entre 100 a $120 \mathrm{~m}$ de profundidade no furo PAP 08 , e entre 79 a $89 \mathrm{~m}$ no furo PAP 09, fato evidenciado pela presença de calcita com tamanho entre 0,5 a $3 \mathrm{~mm}$. No furo PAP 08 , entre 20 a $30 \mathrm{~m}$ c entre 100 a $110 \mathrm{~m}$ de profundidade, ocorrem "intercalações" de siltito de cor cinza de rochas da Formação Diamantino (Fig. 4), que devem representar xenólitos das rochas encaixantes. Microscopicamente, a intrusão Piranha 1 contém macro c megacristais de olivina serpentinizada (45\%), flogopita (25\%), granada piropo $(8 \%)$, ilmenita magnesiana $(6 \%)$, diopsídio $(2 \%)$ e raramente perovskita e espinélio, em uma matriz fina
(14\%) de pseudomorfos de olivina, serpentina e calcita, definindo uma textura inequigranular média a fina e holo-cristalina. Os minerais secundários, como produto de alteração, incluem calcita, serpentina e óxido de lerro. Com base na descrição petrográfica o kimberlito Piranha I é um serpentina flogopita kimberlito.

Alabama As primeiras informações sobre essa intrusão, assim como um levantamento magnetométrico e a descrição de um furo de sondagem (PAD-05), foram apresentadas em um mapeamento geológico realizado por Macedo et al. (1995). Macroscopicamente, trata-se de uma rocha verde escura, com textura inequigranular e porfiroclástica, possuindo ilmenita $(0,15$ a $1 \mathrm{~cm})$, olivina $(0,2$ a $1 \mathrm{~cm})$, calcita $(0,1$ a $0,8 \mathrm{~cm})$, flogopita $(0,2$ a $0,4 \mathrm{~cm})$ e diopsídio $(0,2$ a $1 \mathrm{~cm})$. O corpo possui xenólitos de rochas encaixantes incluindo siltito e arenito da Fm. Diamantino, de cor variando entre vermelha a marrom escura e dimensões entre 0,1 a $9 \mathrm{~cm}$. Possui também xenólitos de basalto com textura afanítica a fanerítica de cor preta e dimensões entre 0,5 a $50 \mathrm{~cm}$, constituídos de plagioclásio labradorita $(40 \%)$, augita $(30 \%)$, pigeonita $(10 \%)$, olivina $(10 \%)$ e minerais opacos (10\%). A textura dos basaltos é subofítica. Foi obtida uma análise química de elementos maiores e traços de um destes xenólitos (amostra PIRW; Greenwood, 2001) confirmando a natureza tolética deste basalto. Estes xenólitos têm dupla importância: de um lado constituem testemunhos de um evento magmático amostrado pelo kimberlito, e de outro, constituem um limitador da idade da intrusão que é mais nova do que o evento representado pelo xenólito e mais velha do que os basaltos da Fm. Paredão Grande. Levando em conta dados da literatura, estes xenólitos podem ser equivalentes ao basalto Tapirapuã (MT), de idade 197 Ma. (Montes-Lauar 1993). O estudo microscópico do Alabama foi dificultado face ao profundo estado de alteração do corpo. Entretanto, lâminas delgadas puderam ser confeccionadas das porções com segregação carbonática, as quais preservaram em parte as características do kimberlito. Macro e microcristais de olivina subédrica a anédrica e serpentinizados também ocorrem. Em lâmina também foram identificados macrocristais de 


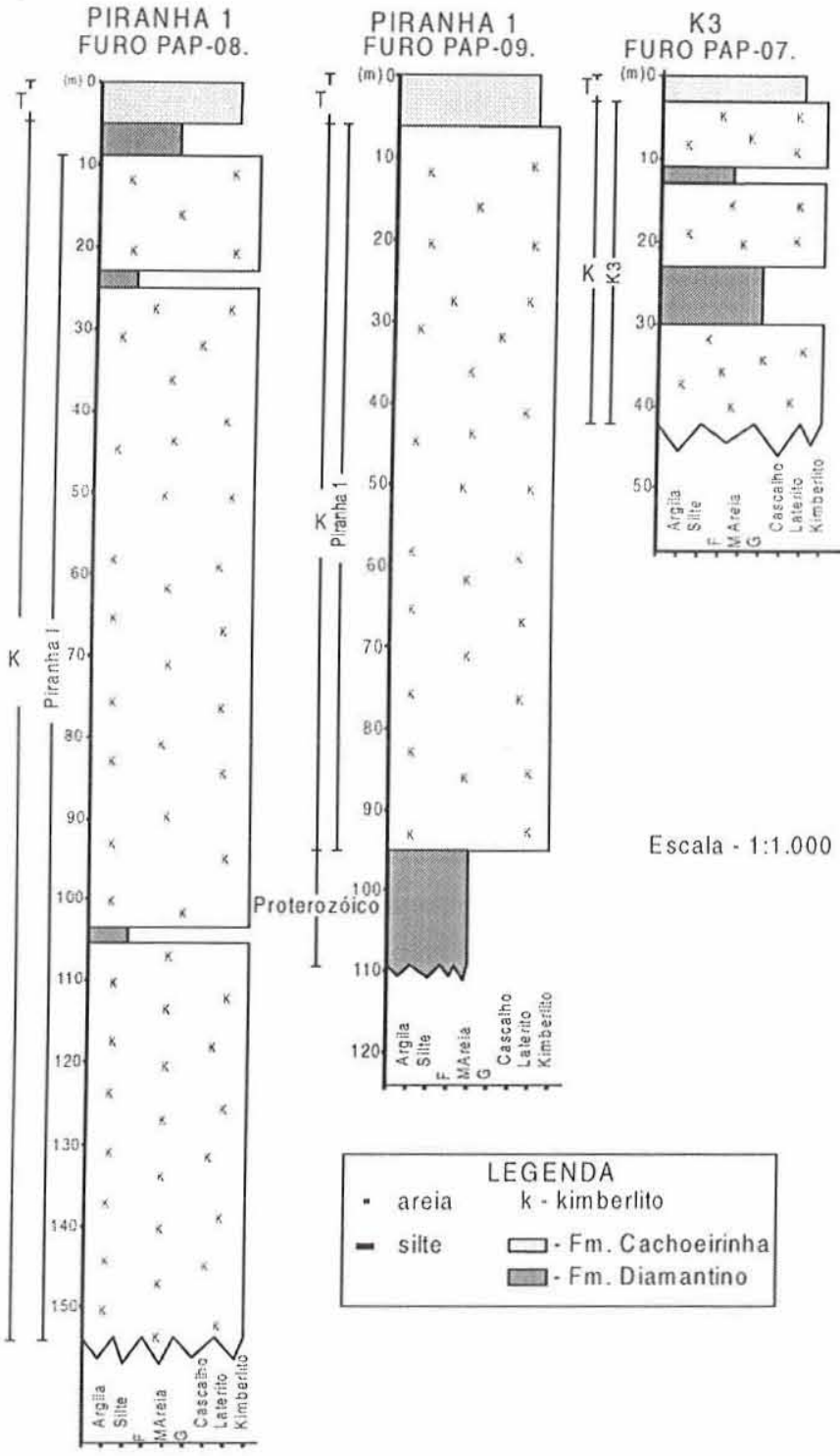

Figura 4 - Furos de sondagem das intrusões K3 e Piranha I.

granada vermelha vinho.

K3 Este é um importante pipe do Campo Kimberlítico de Paranatinga, tendo sido preservado devido a estar parcialmente encoberto por fragmentos de rochas lateríticas terciárias equivalentes a Fm. Cachoeirinha (Gonçalves \& Schneider 1968). O corpo conserva rochas piroclásticas finas a grossas representativas da fácies cratera. A descrição do furo PAP 07 (Fig. 4) mostra que este corpo do ponto de vista textural, é um lapilli tufo, com xenólitos arredondados de arenito e siltito da Fm. Diamantino, por vezes brechados. Em profundidade passa para um kimberlito alterado de cores verde a marrom vermelha, constituindo um tufo kimberlítico. Em poços de $2 \mathrm{~m}$ de profundidade para trabalhos de prospecção, é representado por uma rocha bastante alterada de cor vermelha a marrom, com camadas cíclicas de clastos de cor branca. O conjunto superficial caracteriza um lapilli tufo comum à fácies cratera resultante atividade explosiva em kimberlitos. Associando-se os dados dos poços com os dados obtidos a partir da descrição do Furo PAP 07 (Fig. 4), o K3 contém granadas arredondadas de cor vermelha vinho e ilmenita, ambas com dimensões médias de $3 \mathrm{~mm}$. Diopsídio e flogopita, são menos comuns e de tamanho médio de $2 \mathrm{~mm}$.

Batovi 6 Este é o único corpo da fácies diatrema conhecido no Campo Kimberlítico de Paranatinga até a presente data. Svisero \& Meyer (1986) apresentaram as primeiras informações químicas de alguns minerais resistatos separados da rocha semi-alterada. As granadas revelaram teores médios de $\mathrm{Cr}_{2} \mathrm{O}_{3}$ (2\%), $\mathrm{MgO}(20 \%), \mathrm{CaO}(5 \%)$ e $\mathrm{FeO}(9 \%)$; e as ilmenitas valores de $\mathrm{MgO}$ variando entre 8 a $13 \%$ e $\mathrm{Cr}_{2} \mathrm{O}_{3}$ da ordem de $2,5 \%$ em peso. Costa (1996), comparou a intrusão Batovi 6 com os kimberlitos Limeira I (MG) e Três Ranchos (GO), concluindo que estes três corpos possuem similaridades petrográficas e químicas. Outras características do Batovi 6 são a textura pelletal lapilli e o percentual de $15 \% \mathrm{em}$ volume de xenólitos crustais, que permitiram classificá-lo como uma brecha kimberlítica tufácea (Mitchell 1986). Greenwood et al. (1999), apresentaram dados a respeito dos tipos de fácies, petrografia, química mineral e geoquímica de alguns pipes incluindo o Batovi 6. Do ponto de vista mineralógico, este corpo é constituido por olivinas serpentinizadas, megacristais de granada e ilmenita, perovskita e mais raramente flogopita e diopsídio. A matriz é constituída de serpentina e calcita secundárias, com perovskita e cristais pequenos de ilmenita. Os xenólitos presentes são mantélicos (granada lherzolito) com tamanho superior a $5 \mathrm{~cm}$. Nos estudos de química mineral, Greenwood et al. (1999) identificaram granada G9 no interior de um xenólito de granada Iherzolito.

CONCLUSÕES No decorrer do presente trabalho buscamos descrever elementos específicos até então não conhecidos de algumas intrusões kimberlíticas de Paranatinga, que permitem observar a diversidade das dimensões, forma, área, conteúdo de minerais resistatos e de xenólitos presentes nas intrusões, como é o caso dos corpos Batovi 6, Piranha 1, Alabama e K3. Destacamos as diferenças de tamanho em área dos corpos medidos, como por exemplo: o Piranha 1 atingiu 9,60 ha, sendo o maior estudado, enquanto que o Alabama é o de menor área com 1,06 ha. Quanto à forma das intrusões, a maior parte são elipsoídicas com exceção do K3 que é piriforme.

O conteúdo de minerais resistatos concorda com o observado comumente em outras intrusões kimberlíticas, incluindo granada, ilmenita, diopsídio, espinélio e zircão. Contudo, foram algumas particularidades entre os corpos estudados. Assim sendo, o Alabama se destaca pelo acentuado predomínio de ilmenita fato que pode ser observado visualmente na rocha, no solo de alteração e no leito intermitente da Grota do Ferro (Fig. 3B). A abundância da ilmenita nesta grota é tão grande a ponto de ser responsável pela origem do nome desta drenagem. Diopsídio e zircão gemológicos foram descritos no Piranha 1, predominando no primeiro.

Xenólitos crustais e mantélicos ocorrem nas intrusões e loram identificados a partir do mapeamento geológico e da descrição dos testemunhos de sondagem dos furos PAP 08 e 09, Piranha 1 (Jesus \& Filemon 1997), PAP 07, K3, e PAD 05 ( Macedo et al. 1995). Xenólitos da Formação Diamantino ocorrem em todas as intrusões; contudo, xenólitos de basalto similares à Formação Tapirapuã predominam na intrusão Alabama, enquanto que xenólitos mantélicos (granada lherzolito) são 
abundantes no Batovi 6. Tais informações, associadas aos tipos litológicos descritos nos furos, permitem pressupor que a fácies cratera está preservada nas intrusões Alabama, K3 e Piranha 1, enquanto o Batovi 6 está expondo a fácies diatrema (Mitchell 1986). Os xenólitos similares à Formação Tapirapuã descritos no Alabama também introduzem tais tipos litológicos na estratigrafia adjacente às intrusões kimberlíticas de Paranatinga, uma vez que os basaltos Tapirapuã afloram a aproximadamente $300 \mathrm{~km}$ a oeste destas intrusões.

Com base nas dimensões adotadas por Mitchell (1986) sugerindo um diâmetro de $50 \mathrm{~km}$ para caracterizar um campo kimberlítico, e considerando o contexto geológico das intrusões conhecidas na região de Paranatinga, sugerimos neste trabalho a adoção do conceito de Campo Kimberlítico de Paranatinga ao invés de Província Kimberlítica de Paranatinga, conforme proposto originalmente por Fragomeni (1976) e autores subseqüentes.

O azimute $125^{\circ}$ (Bardet 1973) tem sido utilizado como uma megassutura na crosta sul-americana com mais de $3000 \mathrm{~km}$ de extensão, que controlaria a distribuição de vários campos kimberlíticos ao longo da sua direção, incluindo o Campo Kimberlítico de Paranatinga. Entretanto, alguns elementos estruturais aparentemente se contrapõem a esta idéia. Por exemplo, o Rifte Rio das Mortes (Weska 1996) é uma estrutura distensiva de orientação SW-NE que interrompe o hipotético lineamento. Além disso, o lineamento propriamente dito não alinha corretamente os campos kimberlíticos conhecidos desde o sul de Minas Gerais até o estado de Rondônia. Outro ponto discordante é a ausência de uma grande zona de falha com milonitos que deveria acompanhar o suposto lineamento e que nunca foi observada em campo.

A partir da descrição dos testemunhos de sondagem dos furos PAP 20 e 23 (Fig. 2) e PAD 04, assim como dos corpos de composição basáltica que ocorrem nas margens do rio Batovi e próximo ao rio Ronuro, há nítida associação espacial dos basaltos com as intrusões kimberlíticas. Há também contatos destes basaltos com unidades litoestratigráficas equivalentes do Grupo Bauru, como por exemplo, as formações Cachoeira do Bom Jardim e Cambambe (Weska 1996). Tal contexto vulcanosedimentar do Cretáceo Superior adjacente às intrusões do Campo Kimberlítico de Paranatinga, permite estender os limites do Rifte Rio das Mortes, originalmente identificado a sul no equivalente da Bacia Bauru (Weska 1996), para o norte da Faixa Paraguai nos domínios da Bacia dos Parecis, como resultado do impacto da Pluma de Trindade sob o oeste brasileiro (Gibson et al. 1997, Greenwood 2001).

Agradecimentos A dois revisores anônimos da RBG pelas sugestões ao manuscrito.

\section{Referências}

Abreu S.F. 1973. Recursos minerais do Brasil, 2 ed. São Paulo, Edgard Blücher; Ed. da Universidade de São Paulo, 1: 324p.

Almeida F.F.M. de 1964. Geologia do centro-oeste mato-grossense, Rio de Janeiro, DGM/DNPM, 133p. (Boletim 215)

Bardet M.G. 1973. Geologie du diamant, Paris, Memoires BRGM, 1: 232p.

Barros A.M., da Silva R.H., Cardoso O.R.F.A., Freire F.A., de Souza Jr. J.J., Rivetti M., da Luz D.S., Palmeira R.C. de B.; Tassinari C.C.G. 1982. FoIha Cuiabá, SD. 2I, Projeto RadamBrasil, Ministério das Minas e Energia, Rio de Janeiro, 26: 540p.

Baxter M. 1988. Garimpeiros de Poxoréu, Mineradores de Pequena Escala de Diamantes e seu Meio Ambiente no Brasil, Brasília, Centro Gráfico do Senado Federal, 301p.

Bizzi L.A. \& Pimentel M. 1998. Source characteristics of Brazilian Kimberlites, In: International Kimberlite Conference, Extended Abstracts, 87-88.

Campos D. de A. \& Castro H.E.F. de 1978. Localidades fossilíferas da Folha SD.20 Guaporé, Rio de Janeiro, Projeto RadamBrasil, n.p. (Relatório Interno 203-G).

Costa V.S. 1996. Estudos mineralógicos e químicos do kimberlito Batovi 6 (MT) em comparação com as intrusões Três Ranchos 4 (GO) e Limeira I (MG), Instituto de Geociências, Universidade de Campinas, Campinas. Dissertação de Mestrado em Geociências, 112 p.

Davis G. L. 1977. The age and uranium contents of zircons from kimberlites and associated rocks, In: Boyd Jr. F.R. \& Meyer H.O.A. (eds), International Kimberlite Conference, $2^{\text {ndd }}$, Proceedings, 67-69.

Fragomeni P.R.P. 1976. Controle tectônico da Província Quimberlítica de Paranatinga, Boletim Informativo da Sociedade Brasileira de Geologia, Núcleo Centro-Oeste., 5: 3-10.

Gibson S.A., Thompson R.N., Weska R.K., Dickin A.P., Leonardos O.H. 1997. Late Cretaceous rift-related upwelling and melting of the Trindade starting mantle plume head beneath western Brazil, Contributions to Mineralogy and Petrology, 126: 303-314.

Gonçalves A. \& Schneider R.L. 1968. Geologia de semi-detalhe da região de Sangradouro, Batovi-Tesouro e Guiratinga, Mato Grosso, Ponta Grossa, PETROBRÁS/DESUL, 35p. (Relatório Técnico Interno 370).
Greenwood J. C. 2())I. The secular geochemical evolution of the Trindade mantle plume, University of Cambridge, England, PhD. Thesis, 298p.

Greenwood J. C., Gibson S.A., Thompson R.N., Weska R.K., Dickin A.P. 1999. Cretaceous kimberlites from the Paranatinga-Batovi region, central Brazil: Geochemical evidence for subcratonic lithospheric mantle heterogeneity, In: International Kimberlite Conference, $7^{\text {th }}$, Proceedings, 291-298.

Heaman L., Teixeira N. A., Gobbo L., Gaspar J.C. 1998. U-Pb mantle zircon ages for kimberlites from de Juína and Paranatinga Provinces, Brazil, In: International Kimberlite Conference, $7^{\text {th }}$, Extended Abstracts, 322-324.

Filemon K.E., de Jesus, I.P.S., Weska R.K. 1997. Intrusão kimberlítica Piranhas 1, Paranatinga, MT, In: SBG/ Núcleo Centro-Oeste, Simpósio de Geologia do Centro-Oeste, $6^{\circ}$, Cuiabá, Resumos, 109-110.

King L.C. 1956 - A geomorfologia do Brasil oriental, Revista Brasileira de Geografia, 18(12): 147-265.

Macedo F.C., Freitas C.I., Silveira E.V.G., Arioldi E. 1995. Contribuição à geologia regional e o kimberlito Alabama, Paranatinga, Mato Grosso, Departamento de Recursos Minerais, Instituto de Ciências Exatas e da Terra, Universidade Federal de Mato Grosso, Cuiabá, Monografia de Graduaçĩo em Geologia, 45p.

Mitchell R.H. 1986. Kimberlites: mineralogy, geochemistry, and petrology. New York, Plenum Press, 442p.

Montes-Lauar C. R. 1993. Paleomagnetismo de rochas mesozóico-cenozóicas da plataforma sul-americana: estudo das formações Anari (RO) e Tapirapuã (MT), da ilha São Sebastião (SP), dos complexos alcalino-carbonatíticos de Tapira (MG), Salitre (MG) e das illas do arquipélago dos Abrolhos (BA), Instituto Astronômico e Geofísico, Tese de Doutorado, 206p.

Pinho, M.J. Coêlho N.R., Pisani Jr, W.T. 1994. Dados geológicos e geofísicos das intrusões kimberlíticas na Província Kimberlítica de Paranatinga, MT, Departamento de Recursos Minerais, Instituto de Ciências Exatas e da Terra, Universidade Federal de Mato Grosso, Cuiabá, Monografia de Graduação em Geologia , 61 p. (inédito).

Roxo M.G.O. 1937. Notas geológicas sobre a Chapada do Mato Grosso, Notas Preliminares e Estudos do Serviço Geológico e Mineralógico, Ministério da Agricultura, Rio de Janeiro, 15:4-7. 
Santos J. O. S. \& Loguercio S. O. C. 1984. A parte meridional do craton amazônico (Escudo Brasil-central) e as bacias do Alto Tapajós e Parecis-Alto Xingu, In: Geologia do Brasil, texto explicativo do mapa geológico do Brasil e da área adjacente incluindo depósitos minerais-escala 1:2.500.00(), DNPM, cap. III, $93-127$.

Svisero D.P. \& Chieregati L.A. 1991. Contexto geológico de kimberlitos, lamproítos e ocorrências diamantíferas do Brasil. Boletim. Instituto de Geociências, USP, 75-81 (Publ. Esp. 9).

Svisero D.P. \& Meyer H. O. A. 1986. New occurrences of kimberlite in Brazil, In: International Kimberlite Conference, $4^{\text {th }}$, Extended Abstracts, 145-147.

Weska R.K., Leonardos H.O., Gonzaga G.M. 1993. Simpósio Brasileiro de Geologia do Diamante, $1^{\circ}$, Cuiabá, MT, Brasil, Roteiro de Excursão, Resumos, Resumos Expandidos e Palestra, Ed. UFMT-Gráfica Universitária, 63 p. (Publicaç̧̃̃o Especial 01/93).

Weska R.K. 1996. Geologia da região diamantífera de Poxoréu e áreas adjacentes, Mato Grosso, Departamento de Mineralogia e Petrologia, Instituto de Geociências, Universidade de São Paulo, São Paulo, Tese de Doutorado, $219 \mathrm{p}$.

Weska R.K. \& Svisero D.P. 2001. Uma síntese do conhecimento sobre as rochas de natureza kimberlítica da porção sul do Craton Amazônico, no estado de Mato Grosso, In: Geology of the SW Amazonian Craton: Stat of the Art, Extended Abstracts, São Paulo, SP, Brasil, 140-144.

Manuscrito A-1306 Recebido em 25 de novembro de 2001 Revisão dos autores em 19 de dezembro de 2001 Revisão Aceita em 20 de dezembro de 2001 